\title{
PERDAS VISÍVEIS NA COLHEITA MECANIZADA DE CANA-DE- AÇÚCAR CRUA SOB VELOCIDADES DE DESLOCAMENTO DA COLHEDORA
}

\author{
SEGATO, Silvelena Vanzolini ${ }^{1}$ \\ DAHER, Fábio ${ }^{2}$
}

\begin{abstract}
RESUMO: O objetivo deste experimento foi estudar as perdas visíveis que ocorrem na cultura da cana-deaçúcar crua durante a colheita mecanizada sob duas velocidades de deslocamento da colhedora. O trabalho foi realizado na cidade de Barretos em julho de 2009. A colhedora utilizada foi a John Deer modelo 3510, onde no tratamento 1 ficou ajustada com pressão de corte de base de 1070 Psi e pressão do exaustor de 1050 Psi e velocidade de $8 \mathrm{~km} \mathrm{~h}^{-1}$ e para o tratamento 2 pressão de corte de base de 950 Psi e pressão do exaustor de 1000 Psi, com velocidade variando de $6,5 \mathrm{a} 7 \mathrm{~km} \mathrm{~h}^{-1}$. A distância inicial para o início do ponto de amostragem foi de $30 \mathrm{~m}$ do carreador e cada ponto avaliado teve $10 \mathrm{~m}$ por $2 \mathrm{~m}$ e $50 \mathrm{~m}$ de distância um do outro, sendo todos em linha. O delineamento utilizado foi inteiramente casualizado (DIC), tendo cinco repetições. Os resultados de cada tipo de perda (toco, tolete, pedaço, ponteiro, cana inteira e perda total) foram submetidos à análise de variância e as médias dos tratamentos comparadas pelo teste Tukey a 5\% de probabilidade. No trabalho concluiu-se que há significativo aumento de perda visível quando se usa maior velocidade de deslocamento da colhedora associado à maior pressão de corte de base e do exaustor.
\end{abstract}

Palavras-chave: Saccharum spp. Pressão do corte de base. Pressão do exaustor. Velocidade de colheita.

SUMMARY: The objective of this experiment was to study the visible losses that occur in the culture of sugarcane during the mechanical harvesting of sugarcane in two speeds of displacement of the harvester. The study was conducted in the city of Barretos, Brazil, in July 2009. The harvester used was the John Deer model 3510, where for treatment 1 (V 1), was fitted with pressure to cut base of 1070 psi and the exhaust pressure of $1050 \mathrm{psi}$ and a speed of $8 \mathrm{~km}$ per hour and for treatment 2 (V 2), cutting pressure of 950 psi base pressure and the exhaust of $1000 \mathrm{Psi}$, with speed ranging from 6.5 to $7 \mathrm{~km}$ per hour. The initial distance to the top of the sampling point was 30 meters from the carrier and each point was measured $10 \mathrm{~m}$ by $2 \mathrm{~m}$ and was 50 feet away from each other, and in all lines. In this study it was concluded that no increase in losses when the variables are greater speed, more pressure to cut base and the hood.

Keywords: Saccharum spp. Pressure to cut base and exhaust. Speeds harvest.

\section{INTRODUÇÃO}

A Lei Estadual, 11.241, de 19 de setembro de 2002, obriga que as usinas eliminem de forma gradativa o corte de cana queimada, sendo totalmente eliminado até 2014 para áreas com até $12 \%$ de declividade, e para áreas acima de 12\%, o prazo estende-se até 2017 (MORAES, 2007; PAULILLO et al., 2007; TRIBUNA DE ITUVERAVA, 2009).

A colheita de cana crua manual é inviável, e o trabalhador cortará menos ( de 6 para 3 toneladas por dia por empregado), isso acarretará em aumento de pessoas e inviabilizará o

\footnotetext{
${ }^{1}$ Professor Doutor do Centro Universitário Moura Lacerda - CUML e da Faculdade Dr. Francisco MaedaFAFRAM/FE, Ituverava-SP. E-mail: sv.segato@bol.com.br ${ }^{2}$ Aluno do curso de Agronomia do Centro Universitário Moura Lacerda - CUML.
} 
livre mercado. A colheita mecânica em cana crua é economicamente mais eficiente, por ter menor custo de produção (VEIGA FILHO, 1999).

A região de Ribeirão Preto, SP é caracterizada por ter predominância de grandes propriedades de cana-de-açúcar, e está a frente com colheita mecanizada, portanto além da lei, existe a competitividade entre as usinas, o que faz com que se evolua na fabricação de novas colhedoras que sejam mais eficientes no trabalho, menores, tenham menos perdas e atendam terrenos com maior declividade (MORAES, 2007).

É preciso que se avaliem as perdas geradas em campo pela colheita de cana crua para que se corrijam as falhas operacionais, e, para a correção das mesmas é necessário que se treinem os operadores das colhedoras, que se faça acompanhamento técnico e avaliação do talhão, avaliando também o sincronismo entre colhedora e caminhão (BENEDINI et al., 2009).

Neves et al. (2006) relataram que não é a velocidade de deslocamento da colhedora que interfere na mesma, e sim o gradiente do fluxo de ar na câmara de limpeza, que apresenta grande variação na velocidade do ar. Benedini et al. (2009) relataram que existem diversos fatores relacionados a perdas visíveis, dentre elas estão: variedade, preparação da área, treinamento do profissional, velocidade da colhedora e por fim a manutenção de todo equipamento.

Na colheita mecanizada da cana-de-açúcar, vê-se que existem algumas características próprias que interagem entre solo, planta e máquina, e que pode vir trazer perdas no campo, desde a qualidade da matéria prima até redução do número de cortes do canavial (SALVI et al., 2007).

Neves et al. (2004) classificaram as perdas como visíveis e invisíveis. As visíveis representam colmos inteiros e/ou suas frações, rebolos e tocos resultantes no corte basal. Caso a colhedora puxe a cana com soqueira, o canavial terá problemas na rebrota e a terra e outras impurezas presentes na cana a ser moída oneram os custos de transporte e manutenção de equipamentos industriais e reduzem a eficiência de moagem e extração de sacarose (KROES; HARRIS, 1996; VOLPATO, 2001). As invisíveis são constituídas por caldo, pequenas partículas de cana decorrentes da ação dos mecanismos rotativos que cortam, picam e limpam a cana durante o processamento interno nas máquinas.

Muitos trabalhos científicos já foram feitos a fim de avaliar o real desempenho dessas colhedoras de cana, tanto relacionados ao desempenho operacional (DICK, 1986; DICK; HILTON, 1992; KROES; HARRIS, 1999; RIPOLI et al., 2001; SALVI et al., 2007) quanto as perdas que este poder ter da matéria prima no campo e na colhedora ( RIPOLI et al., 1996; 
NEVES et al., 2003; NEVES et al., 2006).

Para Junqueira et al. (2008), a colheita mecanizada exige ainda variedades de cana com características especiais como: raízes mais resistentes ao arranque mecânico; cana de porte mais ereto; maior facilidade de despalhamento e com um sistema de brotação que consiga romper a camada de palha que fica disposta no solo após a colheita.

As perdas são inevitáveis em qualquer modalidade de colheita, porém a mecanizada, de acordo com medições realizadas pelo Centro de Tecnologia Canavieira (CTC), ocorre perda de cerca de $10 \%$ da matéria prima colhida, o que representa um prejuízo da ordem de US\$ 450 milhões por ano (MAGALHÃES et al., 2006).

Segundo Volpato et al. (2002), no corte mecanizado de cana-de-açúcar, os cortadores de base exercem influência direta nas perdas e na contaminação da matéria-prima com o solo, bem como nos possíveis danos causados à soqueira. Neves et al. (2004) quantificaram as perdas de massa remanescente em lavouras de cana-de-açúcar submetidas à colheita por meio de colhedora automotriz operando sob duas diferentes rotações do ventilador e do extrator primário do equipamento, onde essas foram de $1.200 \mathrm{rpm}$ e $1.500 \mathrm{rpm}$. E neste estudo foi comprovado que ocorreram as maiores perdas para a maior velocidade, com 5,68\% para perdas totais (correspondente a perdas em rebolos, tocos, colmos, pedaços e lascas), 17,38\% para as perdas de massa foliar e totalizou $23,06 \%$ da base úmida. Na menor velocidade houve perdas, porém menor que a anterior, chegando a 2,51\% para as mesmas perdas totais e de $10,74 \%$ para perdas de massa foliar, totalizando $13,25 \%$. Dentro das perdas totais, a fração toco correspondeu a somente $0,08 \%$ para $1.500 \mathrm{rpm}$ e $0,14 \%$ para $1.200 \mathrm{rpm}$.

Segundo Kroes e Harris (1996) e Volpato (2001), a colhedora de cana tem um componente que origina alguns problemas e este é o cortador de base, que devido à deflexão e à deficiência no controle da altura de corte, provoca danos na soqueira, e causa perdas de matéria prima, redução do número de colmos e da qualidade tecnológica da cana colhida. As perdas são constituídas de massa deixada no campo, e a população de colmos é reduzida por duas maneiras: soqueiras destruídas ou removidas mecanicamente e por deterioração, devido aos danos por cisalhamento dos tocos, o que facilita o ataque de pragas e doenças. A cana colhida tem sua qualidade tecnológica reduzida, com o cortador de base, por rebolos fragmentados sujeitos a contaminação e a incorporação de terra, caso as lâminas dos discos dos cortadores trabalharem em contato ou abaixo da superfície do solo, e se o sistema radicular de soqueiras arrancadas forem carregados com a cana. A terra e outras impurezas presentes na cana a ser moída oneram os custos de transporte e manutenção de equipamentos industriais e reduzem a eficiência de moagem e extração de sacarose.

Neves et al. (2006) analisaram o comportamento da colhedora de cana-de-açúcar 
picada frente a dois fluxos de alimentação de matéria prima, mensurando-se as perdas invisíveis, impossíveis de serem quantificadas diretamente no campo, a eficiência de limpeza da colhedora e a velocidade do ar na saída dos extratores. Pelos resultados obtidos, pode-se afirmar que o baixo desempenho das colhedoras, expresso pelos altos índices de perdas de matéria-prima, ou a baixa eficiência de limpeza não está associado à velocidade de deslocamento da colhedora ou ao potencial de produção do canavial. Esse desempenho está relacionado ao gradiente do fluxo de ar na câmara de limpeza, que apresenta grande variação na velocidade do ar, interferindo na capacidade de limpeza da colhedora e, por consequiência, nas perdas totais, visíveis e invisíveis.

Benedini et al. (2009) relataram que as perdas visíveis estão associadas às características da área a ser colhida e também à operação em si da colheita. As prováveis causas para cada tipo de perda visível acima do padrão na colheita mecanizada são comentadas por Salvi (2006).

Para Benedini et al. (2009) a quantificação destas perdas facilita as correções de falhas operacionais. As referentes às características do canavial poderão ser apenas minimizadas, principalmente com a redução da velocidade da colheita. Assim, para a redução das perdas o Centro de Tecnologia Canavieira (CTC) (BENEDINI et al., 2009) sugere treinamento dos operadores de colhedora e acompanhamento da operação durante a safra por técnico da área de treinamento e capacitação tecnológica analisando as condições do talhão, tombamento da cana, comprimento de trabalho, sistema de caminhamento e aceiro, altura de trabalho do corte de base/corte de ponta, velocidade da colhedora, sincronização colhedora/caminhão, distribuição dos equipamentos na área, cultivo e quebra do meio (lombo).

Neves et al. (2004) relataram que as perdas visíveis no campo foram da ordem de $5 \%$. Ripoli et al. (2001) afirmaram que além do custo da tonelada de cana-de-açúcar diminuir com a colheita mecanizada, a capacidade efetiva e operacional de campo aumentou com o aumento da velocidade, e desta maneira as perdas de cana não aumentaram com o aumento da velocidade.

Para Benedini e Silva (2010) valores de perdas na colheita mecanizada próximos de 34 toneladas por hectare são consideráveis aceitáveis.

Por meio desta mecanização que os canaviais estão exigindo na colheita é que o trabalho se faz necessário. Assim, o ensaio objetivou analisar a influência do aumento na velocidade de deslocamento da colhedora nas perdas visíveis de matéria prima. 


\section{MATERIAL E MÉTODOS}

\section{Condução do experimento.}

O experimento foi conduzido na Fazenda Pavão, localizado no município de Barretos, Estado de São Paulo no dia 24 de julho de 2009.

\section{Caracterização do experimento}

\section{Área}

O local tem declividade menor que 20\%, e área de 10,98 hectares.

\section{Descrição do canavial e da variedade}

A variedade de cana utilizada no experimento foi a RB835486, que estava no sexto corte, sendo que até o quarto corte foi utilizado o método de colheita de cana queimada para esta fazenda.

Não foi utilizado nenhum maturador na variedade.

A produção real foi de 79,20 toneladas por hectare, somando então para o talhão inteiro 869,61 toneladas em 10,98 hectares.

Após a colheita, a Usina forneceu os dados de sacarose (PCC de 14,98\%), fibra (12,03\%), pureza (PZA de 88,05\%) e açúcar total recuperado (ATR de 147,44).

De acordo com Agrodon (2009), quando o assunto é brotação, esta variedade é classificada como boa em cana-planta e em cana-soca (colheita manual queimada ou mecanizada crua). O perfilhamento é baixo em cana-planta e médio em cana-soca.

De acordo com Agrodon (2009) esta variedade possui crescimento com velocidade regular, seu porte é médio, tem um fechamento de entrelinhas regular, suscetível a tombamento, tem alta produção e sua maturação é de precoce a médio. Quanto a dados laboratoriais tem-se que seu teor de sacarose é alto, fibra é médio, e PUI longo. Pode haver floração eventualmente; sua adaptabilidade é ampla, pois é muito resistente a seca, apresenta pouco chochamento. Apresenta tolerância a herbicidas. Sua época de colheita vai de maio a setembro.

Para doenças esta é: para carvão intermediária; escaldadura resistente; ferrugem intermediária; estria vermelha resistente; falsa estrias vermelhas resistente; mosaico resistente; podridão abacaxi intermediária. Para pragas: é suscetível a nematóide e resistente ao complexo broca-podridão (AGRODON, grupo GEPAGRI - Grupo de Estudo e Pesquisa em Agricultura). 


\section{Colhedora}

Utilizou-se a Colhedora John Deer 3510.

\section{Tratamentos}

O delineamento utilizado foi inteiramente casualizado (DIC), tendo cinco repetições. O experimento teve dois tratamentos: V1, com velocidade de $8 \mathrm{~km} \mathrm{~h}^{-1}$, pressão de corte de base de 1070 Psi e pressão do exaustor de 1050 Psi; e V2, com velocidade de 6,5 a $7 \mathrm{~km} \mathrm{~h}^{-1}$, pressão de corte de base de 950 Psi e pressão do exaustor de 1000 Psi.

\section{Parcelas}

Cada ponto de amostragem teve área de $20 \mathrm{~m}^{2}(10 \mathrm{~m} \mathrm{X} 2 \mathrm{~m})$, resultando cinco parcelas. Para o início de cada ponto foi necessário estar a $30 \mathrm{~m}$ do carreador sendo a distância entre pontos de $50 \mathrm{~m}$. Na Figura 1 tem-se o modelo de amostragem no campo.

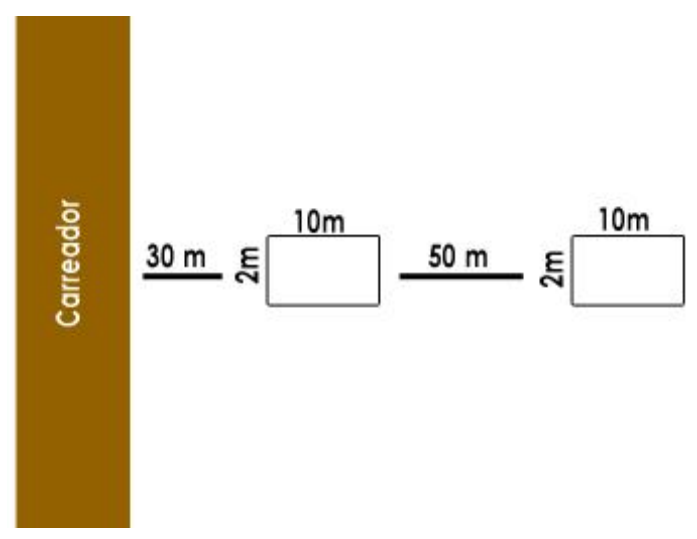

Figura 1. Modelo de amostragem do experimento para comparação de perdas visíveis de cana-de-açúcar, RB835486, colhida a duas velocidades de deslocamento (V1= $8 \mathrm{~km} \cdot \mathrm{h}^{-1}$ e V2 $=6,5 \mathrm{a} 7 \mathrm{~km} \cdot \mathrm{h}^{-1}$ ) da colhedora John Deer 3510. Barretos, SP. 2009.

\section{Avaliações}

Os tipos de perdas visíveis avaliados foram: cana inteira, pedaço, ponteiro, toco, tolete e perda total, conforme Silva et al. (2008). A área de cada amostragem foi de $20 \mathrm{~m}^{2}$, portanto, esse valor foi multiplicado por 500 para chegar a $10000 \mathrm{~m}^{2}$, e desta maneira encontrar toneladas por hectare.

Para as perdas totais foi calculado também o valor em porcentagem, dividindo a perda total $\left(\mathrm{em} \mathrm{t} \mathrm{ha}^{-1}\right)$ pelo valor da produtividade da cana $\left(\mathrm{em} \mathrm{t}^{-\mathrm{ha}^{-1}}\right.$ ) somado ao valor da perda total $\left(\mathrm{em} \mathrm{t}^{\mathrm{h}} \mathrm{h}^{-1}\right)$ e multiplicando por 100 . 


\section{Análise estatística}

Os resultados de cada tipo de perda foram submetidos à análise de variância e as médias dos tratamentos comparadas pelo teste Tukey a 5\% de probabilidade.

Todos os dados foram analisados estatisticamente utilizando-se o programa ESTAT. Este programa estatístico é de domínio público e foi desenvolvido pelo Pólo Computacional da Faculdade de Ciências Agrárias e Veterinárias de Jaboticabal, UNESP, SP.

\section{RESULTADOS E DISCUSSÃO}

Na Figura 2, observam-se todos os dados colhidos no ensaio e verifica-se que houve diferenças significativas nos tratamentos, excetos para perdas em tolete e em pedaço, onde o tratamento com velocidade $8 \mathrm{~km} \mathrm{~h}^{-1}$ acarretou maiores perdas visíveis para toco, ponteira, cana inteira e perda total.

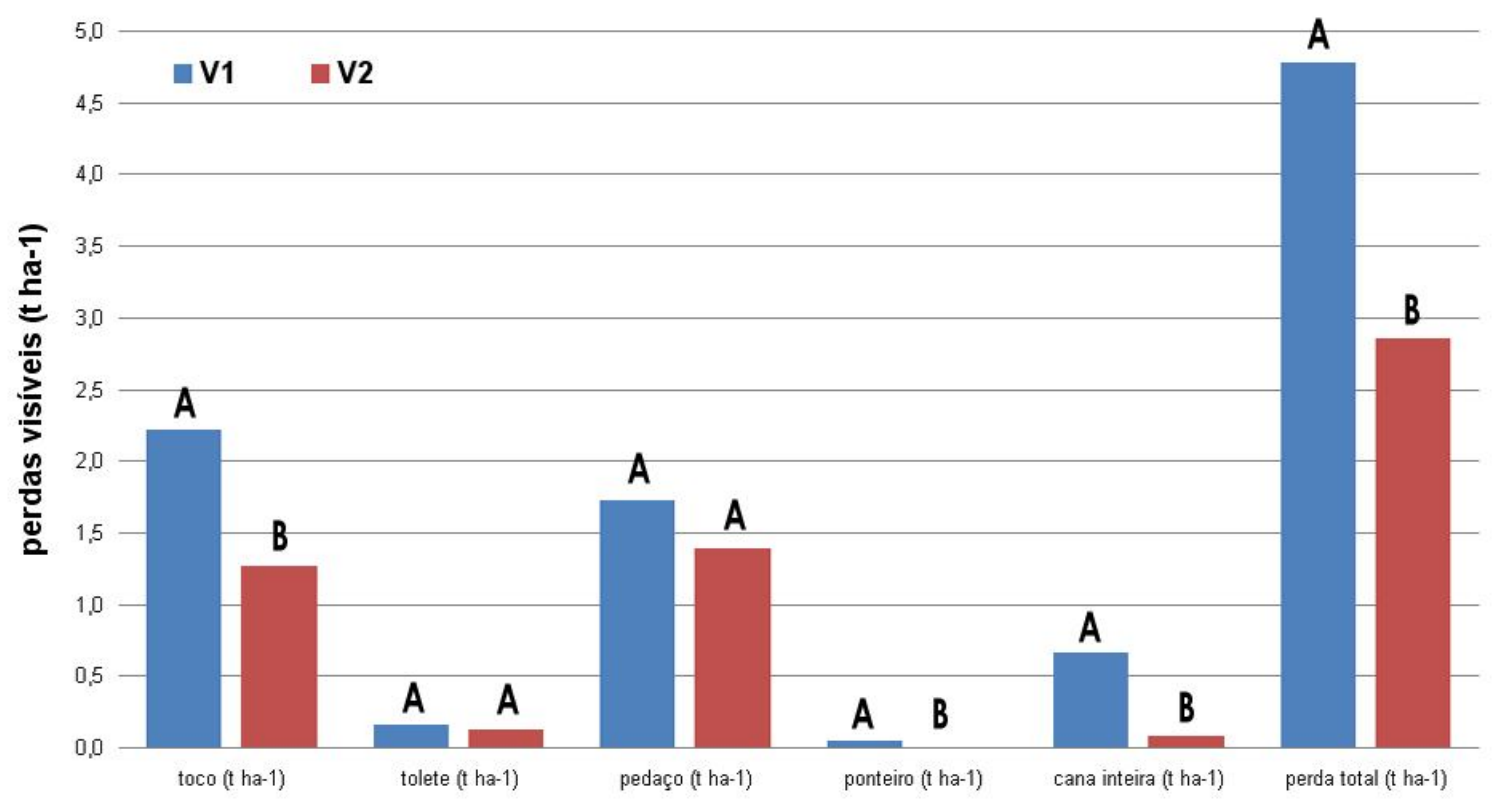

Figura 2. Comparação das médias de perdas por categorias, em toneladas por hectare, de cana-de-açúcar, RB835486, colhida a duas velocidades de deslocamento $\left(\mathrm{V} 1=8 \mathrm{~km} . \mathrm{h}^{-1} \mathrm{e}\right.$ V2 $=6,5$ a $7 \mathrm{~km} \cdot \mathrm{h}^{-1}$ ) da colhedora John Deer 3510. Barretos, SP. 2009. Para cada tipo de perda, médias seguidas por letra distinta diferem entre si pelo teste de Tukey $(\mathrm{P}>0,05)$.

Para toco de cana-de-açúcar (Tabela 1) houve resultado significativo entre os tratamentos, onde para a velocidade maior (V1), a perda foi maior. Contudo, segundo Salvi (2006), as prováveis causas para o tipo de perda "toco" seriam as facas do corte de base 
danificadas ou desgastadas; a caixa do corte de base flutuante travada; áreas com incidência de pedras; solo compactado; nivelamento do solo; acamamento da cana e não a velocidade excessiva da colhedora.

Tabela 1. Comparação das médias de perdas, em $\mathrm{t} \mathrm{ha}^{-1}$, de toco, tolete e pedaço, em cana-deaçúcar, RB835486, colhida a duas velocidades de deslocamento (V1=8 km.h ${ }^{-1}$ e V2 $=6,5$ a 7 $\mathrm{km} \cdot \mathrm{h}^{-1}$ ) da colhedora John Deer 3510. Barretos, SP. 2009.

\begin{tabular}{lccc}
\hline Tratamentos & $\begin{array}{c}\text { Perdas de toco } \\
\left(\mathrm{t} \mathrm{ha}^{-1}\right)\end{array}$ & $\begin{array}{c}\text { Perdas de tolete } \\
\left(\mathrm{t} \mathrm{ha}^{-1}\right)\end{array}$ & $\begin{array}{c}\text { Perdas de pedaço } \\
\left(\mathrm{t} \mathrm{ha}^{-1}\right)\end{array}$ \\
\hline V1 & $2,2125 \mathrm{~A}$ & $0,1625 \mathrm{~A}$ & $1,7250 \mathrm{~A}$ \\
V2 & $1,2600 \mathrm{~B}$ & $0,1200 \mathrm{~A}$ & $1,3900 \mathrm{~A}$ \\
\hline CV $(\%)$ & 48,5162 & 69,3142 & 34,3369 \\
DP & 0,8167 & 0,0963 & 0,5284 \\
DMS & 1,2939 & 0,1525 & 0,8372
\end{tabular}

Médias seguidas de letras maiúsculas diferentes, na mesma coluna, diferem significativamente entre si, pelo Teste de Tukey 5\%. Legenda: CV: coeficiente de variação; DP: desvio padrão e DMS: diferença mínima significativa.

Na Tabela 1 tem-se a comparação das médias de perdas de tolete pelo teste Tukey, e verifica-se que não houve diferença significativa para as duas velocidades avaliadas o que pode significar bom sincronismo entre colhedora e transbordo e cargas não excessivas segundo Salvi (2006). Benedini e Silva (2010) acrescentam às facas do sistema síncrono de corte. De fato, segundo esses autores, a velocidade não se associa a esse tipo de perda.

Para perdas de cana em pedaço, o teste Tukey mostrou que não houve diferença entre os tratamentos, portanto, a maior velocidade foi estatisticamente igual à menor velocidade, conforme os dados contidos na Tabela 1. Contudo, Salvi (2006) relata que a velocidade excessiva pode influir nesse tipo de perda.

$\mathrm{Na}$ Tabela 2 os dados contidos revelaram que a maior velocidade de deslocamento resultou em maior perda de pontas, contudo o coeficiente de variação foi excessivamente alto, demonstrando grande variabilidade entre as repetições. De fato, Salvi (2006), não associa velocidade de deslocamento da colhedora com perdas de ponteiro. Embora não seja a parte com maior concentração de sacarose, a perda do ponteiro da cana-de-açúcar pode significar prejuízo em caso de cana em plena maturação. 
Tabela 2. Comparação das médias de perdas, em $\mathrm{t} \mathrm{ha}^{-1}$, de ponteiro e de cana inteira, em cana-de-açúcar, RB835486, colhida a duas velocidades de deslocamento (V1= $8 \mathrm{~km} . \mathrm{h}^{-1} \mathrm{e}$ V2 $=6,5 \mathrm{a} 7 \mathrm{~km} \cdot \mathrm{h}^{-1}$ ) da colhedora John Deer 3510. Barretos, SP. 2009.

\begin{tabular}{lcc}
\hline Tratamentos & $\begin{array}{c}\text { Ponteiro } \\
\left(\mathrm{t} \mathrm{ha}^{-1}\right)\end{array}$ & $\begin{array}{c}\text { Cana inteira } \\
\left(\mathrm{t} \mathrm{ha}^{-1}\right)\end{array}$ \\
\hline V1 & $0,5000 \mathrm{~A}$ & $0,6625 \mathrm{~A}$ \\
V2 & $0,0 \mathrm{~A}$ & $0,0800 \mathrm{~B}$ \\
\hline CV $(\%)$ & 294,5942 & 76,0434 \\
DP & 0,0655 & 0,2577 \\
DMS & 0,1037 & 0,4083 \\
\hline
\end{tabular}

Médias seguidas de letras maiúsculas diferentes, na mesma coluna, diferem significativamente entre si, pelo Teste de Tukey a 5\%. Legenda: CV: coeficiente de variação; DP: desvio padrão e DMS: diferença mínima significativa.

Na Tabela 2, que compara as perdas de cana inteira, observa-se que houve diferença significativa entre os tratamentos e que com o aumento da velocidade a perda foi maior. Salvi (2006) relatou associação entre perda de cana inteira e velocidade excessiva da colhedora. Este resultado concorda com Neves et al. (2004) o qual constatou que ocorreram maiores perdas para maior velocidade.

A comparação da Tabela 3 confirma que há mais perdas na colheita mecanizada quando a colhedora desloca-se com maior velocidade, pois o resultado entre as médias foi significativo e o coeficiente de variação entre os dados de perda total foi aceitável, em torno de 20\%. Os dados do trabalho discordam dos verificados por Neves et al. (2006) que afirmaram que o baixo desempenho das colhedoras, expresso pelos altos índices de perdas de matéria prima, não está associado à velocidade de deslocamento da colhedora.

Na Tabela 3 verifica-se que a porcentagem de perdas entre os tratamentos foi distinta, superior a 1,5 pontos percentuais, e segundo o CTC, Benedini et al. (2009), seria classificada em alta para a maior velocidade de deslocamento, pois foi superior a 4,5\% e média para a menor velocidade de deslocamento, pois foi compreendida no intervalo entre 2,5 a 4,5\%. Observa-se ainda que as perdas foram de 2,85 t.ha ${ }^{-1}$ para a menor velocidade e de 4,13 t.ha ${ }^{-1}$ para a maior velocidade de deslocamento e segundo Benedini e Silva (2010) valores próximos de 3-4 toneladas por hectare são consideráveis aceitáveis. 
Tabela 3. Comparação das médias de perdas totais em toneladas por hectare, RB835486, colhida a duas velocidades de deslocamento $\left(\mathrm{V} 1=8 \mathrm{~km} \cdot \mathrm{h}^{-1}\right.$ e V2 $=6,5$ a $\left.7 \mathrm{~km} \cdot \mathrm{h}^{-1}\right)$ da colhedora John Deer 3510. Barretos, SP. 2009.

\begin{tabular}{lcc}
\hline Tratamentos & Média $\left(\mathrm{t}^{-h^{-1}}\right)$ & Média $(\%)$ \\
\hline V1 & $4,1333 \mathrm{~A}$ & 4,96 \\
V2 & $2,8500 \mathrm{~B}$ & 3,42 \\
\hline CV $(\%)$ & 22,3187 & \\
DP & 0,7435 & \\
DMS & 1,3284 & \\
\hline
\end{tabular}

Médias seguidas de letras maiúsculas diferentes, na mesma coluna, diferem significativamente entre si, pelo Teste de Tukey a 5\%. Legenda: CV: coeficiente de variação; DP: desvio padrão e DMS: diferença mínima significativa.

Cabe destacar, observando os dados como um todo, que se esperava que com a velocidade excessiva da colhedora aumentassem as perdas de pedaços de cana e isso não ocorreu, contudo toco e ponteiro apesar de ter dado diferença significativa entre os tratamentos não se relaciona com a velocidade de deslocamento da colhedora. $\mathrm{O}$ aumento significativo do componente cana inteira pode estar relacionado à maior velocidade de deslocamento da colhedora. Os dados de perdas totais demonstram que a cana colhida mecanicamente com mais velocidade da colhedora leva a um aumento significativo de perdas no canavial. Em próximo trabalho vale a pena caracterizar melhor os componentes que interferem nos resultados bem como aumentar o número de tratamentos (velocidade menor, média e alta) e repetições, Benedini et al. (2009) sugerem pelo menos 10 repetições.

\section{CONCLUSÃO}

Nas condições em que o ensaio foi conduzido, conclui-se que canaviais colhidos com colhedoras com velocidade de deslocamento de $8 \mathrm{~km} \mathrm{~h}^{-1}$, pressão de corte de base de 1070 Psi e pressão do exaustor de 1050 Psi resultam em aumento de perdas visíveis em relação a velocidade de 6,5 a $7 \mathrm{~km} \mathrm{~h}^{-1}$, pressão de corte de base de 950 Psi e pressão do exaustor de 1000 Psi. 


\section{REFERÊNCIAS}

AGRODON. Características Agroindustriais da RB835486. Disponível em: http://www.agrodon.com.br/LINKRB835486.html. Acesso em: 2 nov. 2009.

BENEDINI, M.S.; SILVA, A.L. Perdas de cana na colheita mecanizada. Canavieiros: a força que movimenta o setor. Sertãozinho, v.5, n.48, p.28-31, 2010.

BENEDINI, M.S.; BROD, F.P.R.; PERTICARRARI, J.G. Perdas de cana e impurezas vegetais e minerais na colheita mecanizada. Boletim. 2009. 7p. Disponível em: http://xa.yimg.com/kq/groups/20144470/1118993118/name/Perdas+de+cana+e+impurezas+v egetais+e+minerais+-+CTC.pdf. Acesso em: 9 nov. 2009.

DICK, R.G. Potential losses higher when harvesting green. BSES Bulletin, Austrália, n.15, p.18-10, Jul. 1986.

DICK, R.G.; HILTON J.D. Sensor and control technology in sugarcane harvesters. In: AUSTRALIAN SOCIETY OF SUGAR CANE TECHNOLOGISTS CONFERENCE, 14., 1992, Mackay. Proceedings... Brisbane: Watson Ferguson, p.179-86. 1992.

JUNQUEIRA, C.P.; STERCHILE, S.P.W.; SHIKIDA, P.F.A. Mudanças no padrão tecnológico do corte de cana-de-açúcar: uma análise do caso paranaense. In: CONGRESSO DA SOCIEDADE BRASILEIRA DE ECONOMIA, ADMINISTRAÇÃO E SOCIOLOGIA RURAL, 46. Anais... Rio Branco, AC, 2008. 23p. Disponível em: http://www.sober.org.br/palestra/9/21.pdf. Acesso em: 10 set. 2010.

KROES, S.; HARRIS, H.D. Knockdown causes major damage to cane during harvesting. Proceedings of Australian Society of Sugar Cane Technologists, Brisbane, v.1, n.2, p.13744, 1996.

KROES, S.; HARRIS, H.D. The optimum harvester forward speed. Zuckerindustrie, Berlin, v.124, n.2, p.126-30, 1999.

MAGALHÃES, P.S.G.et al. Colheita de cana-de-açúcar e palha para a produção de etanol. In: WORKSHOP - COLHEITA, TRANSPORTE E RECUPERAÇÃO DE PALHA, 2., 2006, Campinas: Universidade Estadual de Campinas, 19 p. 2006.

MORAES, M.A.F.D. O mercado de trabalho da agroindústria canavieira: desafios e oportunidades. Revista de Economia Aplicada, São Paulo, v. 11, n. 4, p. 605-619, out.-dez. 2007.

NEVES, J.L.M.et al. Avaliação de perdas invisíveis de cana-de-açúcar nos sistemas da colhedora de cana picada. Engenharia Agrícola, Jaboticabal, v.23, n.3, p.539-46, 2003.

NEVES, J.L.M.; MAGALHÃES, P.S.G.; OTA, W.M. Sistema de monitoramento de perdas visíveis de cana-de-açúcar em colhedora de cana picada. Engenharia Agrícola, Jaboticabal, v.24, n.3, p.764-770, 2004.

NEVES, J.L.M.et al. Avaliação de perdas invisíveis na colheita mecanizada em dois fluxos de massa de cana-de-açúcar. Engenharia Agrícola, Jaboticabal, v.26, n.3, p.787-94, 2006. 
PAULILLO, L. F.et al. Álcool combustível e biodiesel no Brasil: quo vadis? Revista de Economia e Sociologia Rural, Brasília, v.45, n.03. p.531-565, Jul./Set., 2007.

RIPOLI, T.C.; FURLANI NETO, V.L.; NOVA, J. Colheita Mecânica: perdas de matériaprima em canaviais com e sem queima prévia. STAB, Piracicaba, v.14, n.10, p.19-24, 1996.

RIPOLI, T.C.C.et al. Operational and economic performance of green cane chopped harvester, in Brazil, In: INTERNATIONAL ANNUAL MEETING ASAE, Sacramento, 2001.Anais... St. Joseph: ASAE, 2001.

SALVI, J.V. Qualidade do corte de base de colhedoras de cana-de-açúcar. 89f. 2006. Dissertação (Mestrado). Escola Superior de Agricultura Luiz de Queiroz. Universidade de São Paulo. Piracicaba.

SALVI, J.V.; MATOS, M.A.; MILAN, M. Avaliação do desempenho de dispositivo de cortes de base de colhedora de cana-de-açúcar. Engenharia Agrícola, v.27, n.1, p.201-209, 2007.

SILVA, R. P.et al. Controle estatístico aplicado ao processo de colheita mecanizada de canade-açúcar. Engenharia Agrícola, Jaboticabal, v.28, n.2, p.292-304, abr./jun. 2008.

TRIBUNA DE ITUVERAVA. Queima de cana vai até 2014 em todo Estado de São Paulo. Disponível em:

http://www.tribunadeituverava.com.br/VIEW.ASP?ID=4910\&TITULO=AGRICULTURA . Acesso em: 5 out. 2009.

VEIGA FILHO, A. de A. Estudo do processo de mecanização do corte na cana-de-açúcar: o caso do Estado de São Paulo. Recitec, Recife, v. 3, n. 1, p. 74-99, 1999.

VOLPATO, J.L.M. Otimização de um cortador de base flutuante para seguimento do perfil de solo em colhedoras de cana-de-açúcar. 2001. 204 f. Tese (Doutorado em Máquinas Agrícolas) - Faculdade de Engenharia Agrícola, Universidade Estadual de Campinas.

VOLPATO, C.E.S.; BRAUNBECK, O.A.; OLIVEIRA, C.A.A. Desenvolvimento e avaliação de um protótipo de cortador de base para colhedoras de cana-de-açúcar. Revista Brasileira de Engenharia Agrícola e Ambiental, Campina Grande, v.6, n.2, p.345-8, 2002. 